\title{
On Heidegger's Existentialism of Being-in-the-World
}

\author{
Xiao-li YAN \\ School of Foreign Languages, Henan Institute of Engineering, Zhengzhou, China \\ 52453091@163.com
}

Keywords: Worldhood or worldliness, Understanding, Being, Heidegger, Understanding of being .

\begin{abstract}
According to Heidegger, our essential character is our existence which is fundamentally characterized by our being-in-the-world, and the term "the world" in the compound expression only belongs to our human beings because it is co-originally set up with an understanding of being of entities within the world. In Heidegger's words: "What can be meant by describing 'the world' as a phenomenon? It means to let us see what shows itself in 'entities' within the world" (BT, 91; italics added).As far as what has been made clear about an understanding, we know that an understanding is the first ray of light which arises in a relational network to illumine a human being who understands a world, and we also know that the human being who understands exists in his basic state of being-in-the-world.
\end{abstract}

\section{Introduction}

According to Heidegger, our essential character is our existence which is fundamentally characterized by our being-in-the-world, and the term "the world" in the compound expression only belongs to our human beings because it is co-originally set up with an understanding of being of entities within the world. In Heidegger's words: "What can be meant by describing 'the world' as a phenomenon? It means to let us see what shows itself in 'entities' within the world" (BT, 91; italics added). However, how is it possible that "the world" can "let us see what shows itself in 'entities' within the world"? As far as what has been made clear about an understanding, we know that an understanding is the first ray of light which arises in a relational network to illumine a human being who understands a world, and we also know that the human being who understands exists in his basic state of being-in-the-world, so the answer to that question must be necessarily grounded upon an understanding which is obviously equiprimordial with "the world", for "the world" is nothing more than "what shows itself in 'entities" ", and the entities have already been disclosed by an understanding in advance. To combine the upshots, we can simply claim that "It (the world) means to let us see what shows itself in "entities' within the world" is equivalent to "It (the world) means to let us see what an understanding shows itself in 'entities' within the world". Therefore, in Heidegger's mind, an understanding always means an understanding of a phenomenological world (the world), and a phenomenological world (the world) always means a world of understanding or a world which understands.

\section{Heidegger's Anatomy of the Ontological Structures of Being-in-the-World}

When Heidegger existentially anatomizes the ontological structures of Dasein's being-in-the-world, what he concentrates on, except for other constitutive items of this unitary phenomenon, is no more than the question of the "worldhood of the world", 
which can be seen clearly in Section 1, Chapter 3, Part One, BT. Like the "understanding" and the "being", "the worldhood of the world" is not an entity, too. Why is "the worldhood of the world" not an entity within the world? Taylor Carman (2003) has an answer: "In short, the worldliness of the world is the ontological structure of the preconceptual practical intelligibility of things, in virtue of which we can find our way about in any particular world, make use of things, and act in a way that both has purpose and point. It is essential to our existence as Dasein that our being is a being-in-the-world in this ontological-existential sense: 'worldliness is an existentiale" " (HA, 133-34; italics added). In this quotation, what merits our attention is the predicative intelligibility in characterizing the worldhood (worldliness) of the world. We know that intelligibility is cognate with understanding, signifying the capability of understanding or the ability of being understood. Carman's first use of intelligibility appears in this sentence: “... (this) is wrong to confine Heidegger's notions of intelligibility and practice to linguistic meaning and linguistic practice, but ... is right to construe being as intelligibility ..." (HA, 15). And in his analysis of "the meaning of Being" (HA, 13-18), Carman firmly supports Heidegger's notion of the inherently co-original, co-existing relationship between the "being" and the "understanding": " "there is' no being apart from or independent of our understanding of it: ... '[There is a] necessary connection between being and understanding' " (HA, 17). All these facts give us reason to believe that there is no distortion to replace the "intelligibility" with the "understanding" in Carman's answer to the question of the meaning of "the worldliness of the world": In short, the worldliness of the world is the ontological structure of the preconceptual practical understanding of things, in virtue of which we can find our way about in any particular world, make use of things, and act in a way that both has purpose and point ... . Or simply to put it, "the worldliness (worldhood) of the world" is a phenomenological world. Therefore, when "the world" is used in hermeneutic phenomenology, it usually substitutes "the worldliness (worldhood) of the world". That is, talking about or having "the world" in view in the phenomenological context is talking about or having "the worldliness (worldhood) of the world" in view. Here, we have come to such an openness wherein we find that there exists an inherent, co-existing kinship among the "understanding", the "world", the "being", and the "worldhood (worldliness) of the world", and this kinship, to a significant extent, essentially speaks of the existential commensurability among them: not only can one be generally exchanged for another in their use but each in its own scope emphatically lays open some conditions of possibility of understanding of being. This is the profound reason why Heidegger in his hermeneutic phenomenology emphatically calls the human being's most basic existence — being-in-the-world - a unitary phenomenon.

To lay out the necessary connection among "the worldhood of the world", the "world", the "understanding of being" and the "understanding" will give us another vantagepoint to see the leadership of an understanding in our being-in-the-world. The worldhood or the world is not an entity but it discloses entities within the world. Not only that. The worldhood is that which presupposes all kinds of knowing, letting us see entities within the world in terms of their being. Like the understanding, the worldhood is so encompassing, close, and transparent that it always flees from the consciousness or reflective awareness unless we intentionally try to reflect it. Like the understanding, the worldhood makes up the constitution of the "being" of Dasein in the existential-ontological structure of being-in-the-world; and like the understanding, 
though it can never be grasped as an entity, it always is being-with and being-alongside entities (including human beings).

\section{The Relationship between Understanding and Worldliness}

Of course, there is a little difference between the "understanding" and the "worldhood", which is seen only in their different angles of emphasis: the former stresses the basic constitutive element of the latter and hence its character, while the latter emphasizes the constitutive scope or holistic structure of the former and hence its essence: “... the understanding must be through the world. It is fundamental to all understanding; the world and the understanding are inseparable parts of the ontological constitution of Dasein's existing" (Palmer, 1969: 133). Why does "the worldhood of the world" which is penetrated and permeated with the understanding have the status of guidance? To answer this question we have to enter Heidegger's analytics of the network of the worldhood in order to see how this worldhood is constituted and made-up by understanding. After this exploration, we will inevitably come to a conclusion: the worldhood can function as a guidance only because its constitutive and co-original item "understanding" is directional.

In brief, Heidegger's analysis of the worldhood begins with his conception of equipment which is understood as "the being of those entities which we encounter as closest to us can be exhibited phenomenologically if we take as our clue our everyday Being-in-the-world" (BT, 95). In order to elucidate "our everyday Being-in-the-world" or "everyday dealings in the world and with entities within-the-world" (ibid), Heidegger introduces the technical term "readiness-to-hand", which means that it is "not grasped theoretically at all, nor is it itself the sort of thing that circumspection takes proximally as a circumspective theme" (BT, 99; italics added). Therefore, "If we look at Things just 'theoretically', we can get along without understanding readiness-to-hand" (BT, 98). Equipment has the character of readiness-to-hand; it cannot be grasped theoretically or thematically, either. For this reason, equipment is not a piece of equipment; it is a totality of equipment. We cannot grasp equipment without its relation to other equipment. Thus "the being of any equipment always belongs to a totality of equipment, in which it can be this equipment that it is. Equipment is essentially 'something in-order-to ...'. A totality of equipment is constituted by various ways of the 'in-order-to', ... In this 'in-order-to' as a structure there lies an assignment or reference of something to something" (BT, 97). That is, "Equipment — in accordance with its equipmentality - always is in terms of its belonging to other equipment" (ibid). But if we want to get more detailed description about the structure of "the worldhood of the world", only such an analysis of equipment is not enough, for it is literally the beginning step; we must go on the path paved by Heidegger to his more fundamental disclosure: "Involvement and significance: the worldhood of the World" (BT, 114).

The purpose of our following Heidegger's step up to this point remains the same: for elucidating the meaning of "understanding as a guidance". Although the analysis of equipment reveals some clue to our theme, it is still not sufficient. In order to get more explicit the meaning of "understanding as a guidance", it is worthy of undertaking such an exploration to search for evidence in "the aporetic structure of Being and Time, a structure difficult to discern, and whose many interwoven threads can be traced back to the equally multifaceted distinctive status of Dasein, for with this distinctiveness, which 
renders the difference between being and beings equivalent to the Dasein/nonDasein dichotomy, the traditional subject-object schema is tacitly reintroduced" (HW, 21-22).

If the "world" or the "worldhood" is primarily lit up and constituted by the fact of "understanding of being" which is equiprimordial with it, then the "world" or the "worldhood" as a whole system of relationships (as mentioned previously) necessarily demand that an understanding have a kind of structure of relations, references, or assignments to meet that demand. Even though in the section entitled "Involvement and Significance: the Worldhood of the World" $(\mathrm{BT}, 114)$ the meaning of "understanding of being" is largely kept to the position of background, yet according to Lafont's remark, all the analysis of this section can be traced back to the subject of "understanding of being", because Heidegger defines that Dasein is essentially constituted by its understanding of being. In fact, to explicate an understanding as a kind of structure of relating or assigning something to something else is the explication of the transcendence of an understanding in terms of its essentially existential character. An understanding at one end connects itself with one who understands, at the other end unifies itself with what is thus understood. An understanding with such a structure of transcendence necessarily requires "letting something be involved" (BT, 116). What is the most involved and therefore closest to us is that which first constitutes what Heidegger calls "the ready-to-hand as equipment" whose constitutive state "is one of reference or assignment" (BT, 114). The "reference" or "assignment" just indicates the relationship of "with ... in ..." which means "letting something be involved". Being involved or involvement is "the character of Being which belongs to the ready-to-hand" (BT, 115).

An involvement is a kind of understanding of being, it needs what is involved to be set free for such an involvement, and finally for an understanding, otherwise there will be no involvement or understanding. An involvement is a sort of relational structure which expresses what an understanding has: "towards-which" and "for-which". "The totality of involvements itself goes back ultimately to a 'towards-which' in which there is no further involvement" (BT, 116). In this structure there implies a purposive relationship, for "the primary 'towards-which' is a 'for-the-sake-of-which'. But the 'for-the-sake-of' always pertains to the Being of Dasein" (BT, 116-17). In other words, the structure of involvement is a structure of "interconnection" which "leads to Dasein's very Being as the sole authentic 'for-the-sake-of-which' " (BT, 117).

\section{Conclusion}

Although an involvement is a kind of understanding of being, yet it is already a derivative mode of an understanding from the original one. Because "letting something be involved" already signifies "we let something ready-to-hand be so-and-so as it is already and in order that it be such" (BT, 117). Here, an involvement is a kind of clue which leads us to discover and encounter what is involved in its "readiness-to-hand", thus "letting something be involved is the condition for the possibility of encountering anything ready-to-hand" (ibid). Before a single involvement is called into attention, a totality of involvements must be awoken, "an involvement is itself discovered only on the basis of the prior discovery of a totality of involvements" (BT, 118). More generally, "in any involvement that has been discovered (that is, in anything ready-to-hand which we encounter; added), what we have called the 'worldly character' of the ready-to-hand has been discovered beforehand" (ibid). 


\section{References}

[1] Heidegger, Martin. Being and Time. John Macquarrie \& Edward Robinson (trans.) China Social Sciences Publishing House Chengchengh Books Ltd., 1999.

[2] Norris, Christopher. Deconstruction: Theory and Practice. London and New York: Methuen Co. Ltd., 1982.

[3] Palmer, Richard E. Hermeneutics -- Interpretation Theory in Schleiermacher, Dilthey, Heidegger, and Gadamer. Evanston: Northwestern University Press, 1969. 